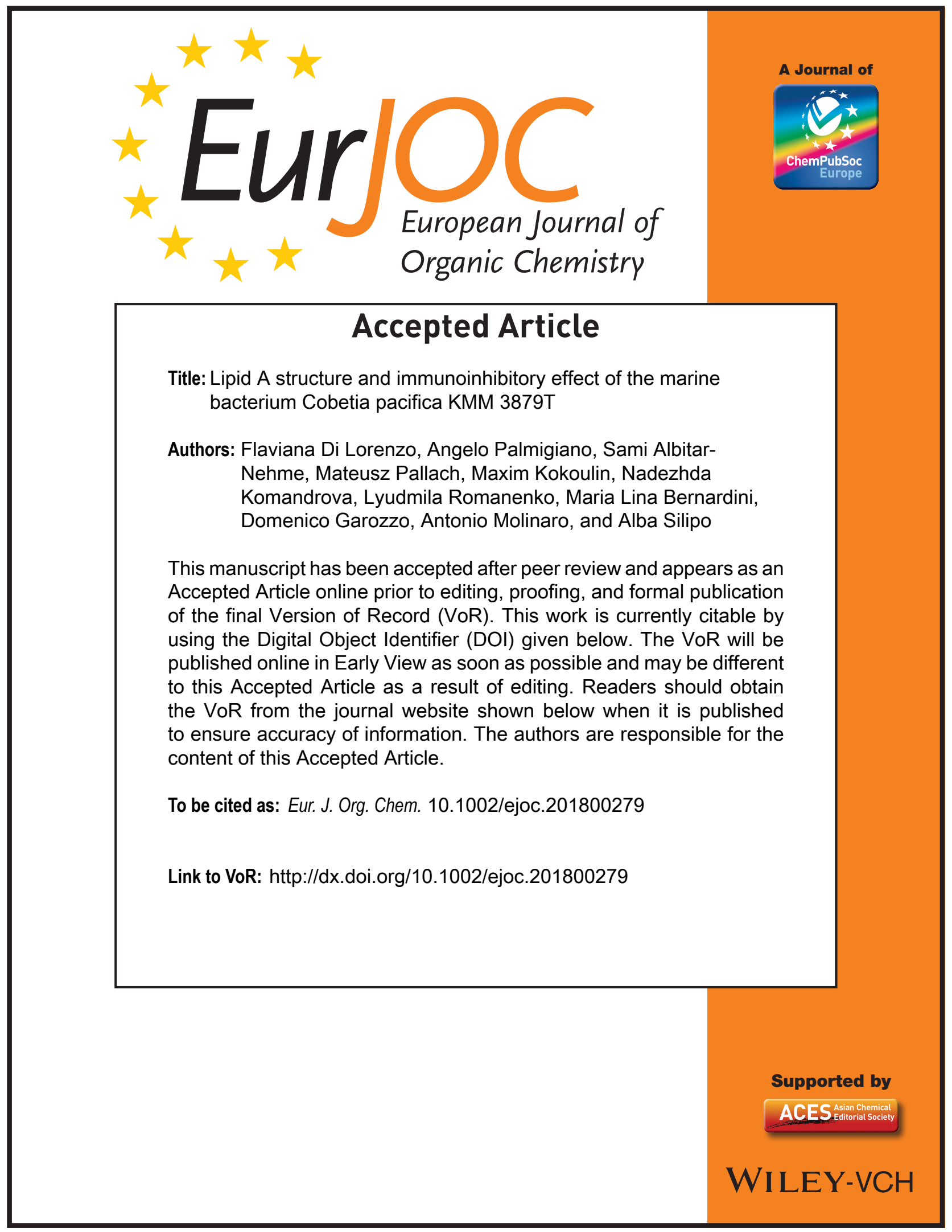


WILEY-VCH

\title{
Lipid A structure and immunoinhibitory effect of the marine bacterium Cobetia pacifica KMM $3879^{\top}$
}

\author{
Flaviana Di Lorenzo, ${ }^{*[a]}$ Angelo Palmigiano, ${ }^{[b]}$ Sami Albitar-Nehme, ${ }^{[c]}$ Mateusz Pallach, ${ }^{[a]}$ Maxim \\ Kokoulin,,$^{[d]}$ Nadezhda Komandrova, ${ }^{[d]}$ Lyudmila Romanenko, ${ }^{[d]}$ Maria Lina Bernardini, ${ }^{[c]}$ Domenico \\ Garozzo, ${ }^{[b]}$ Antonio Molinaro, ${ }^{[a]}$ Alba Silipo*[a]
}

\begin{abstract}
The structural elucidation of lipopolysaccharides (LPSs) from Gram-negative marine bacteria, in addition to the assessment of their immunological properties, is a fascinating and active research field, not only because it can give insight to aid understanding of adaptation phenomena occurring in the marine environment but also it opens new perspectives of design and development of novel immunoregulatory drugs. Here we report the structural characterization of the lipid A component of the LPS isolated from the marine bacterium Cobetia pacifica KMM $3879^{\top}$, characterized by a family of species differing in the acylation pattern. The structure has been achieved by extensive chemical analyses and matrix-assisted laser desorption/ionization (MALDI) mass spectrometry. Moreover, cellular immunology studies on the LPS highlighted its low immunostimulatory impact and a very interesting and promising inhibitory activity of the toxic effects of Escherichia coli LPS.
\end{abstract}

\section{Introduction}

Marine bacteria have adapted, over millions of years, to survival in adverse conditions as marine environments are often characterized by one or more extreme chemical or physical parameters, such as high salinity, low temperature and elevated pressure. ${ }^{[1]}$ The adaptation process has been accomplished by developing several and complex processes involving modification of cell structural components (i.e. proteins, nucleic acids, membrane lipids) in order to assure a shield from the disrupting action of natural stress factors. Therefore, most of the structural peculiarities observed for bacterial components can be seen as a

[a] F, Di Lorenzo; M, Pallach; A, Molinaro; A, Silipo Department of Chemical Sciences University of Naples Federico II via Cinthia 480126 Naples, Italy E-mail: flaviana.dilorenzo@unina.it; silipo@unina.it

[b] A, Palmigiano; D, Garozzo CNR-Istituto per i Polimeri Compositi e Biomateriali IPCB Via P. Gaifami 18, 95126 Catania, Italy

[c] S, Albitar-Nehme; ML, Bernardini Department of Biology and Biotechnology "Charles Darwin" Sapienza - University of Rome Piazzale Aldo Moro 5, 00185 Roma, Italy

[d] M, Kokulin; N, Komandrova; L, Romanenko G.B. Elyakov Pacific Institute of Bioorganic Chemistry, Far East Branch of the Russian Academy of Sciences, Svetlanskaya St 50, 690022 Vladivostok, Russia

Supporting information for this article is given via a link at the end of the document. response to the evolutionary pressure exerted by the marine environment. ${ }^{[1]}$

Gram-negative bacteria are widespread in marine habitats, of which constitute a considerable part of the microbial community. A hallmark of most of Gram-negative bacteria is their asymmetric outer membrane whose surface is mostly covered by lipopolysaccharides (LPS), which are in direct contact with the external environment and, as such, play an important role in protection towards the outside dangerous agents. ${ }^{[2]}$ In addition to their fundamental structural function in contributing to the cell homeostasis by affecting cellular rigidity and permeability, LPSs are involved in many aspects of host-bacterium interaction events such as, among others, colonization, symbiosis and virulence. ${ }^{[3-5]}$ Importantly, in mammals, LPS is specifically recognized by the innate immune receptor complex constituted by Toll-like receptor 4 (TLR4) and myeloid differentiation protein-2 (MD-2) ${ }^{[3-5]}$ As a consequence of the recognition event, a rapid release of pro-inflammatory cytokines, which in turn regulates adaptive immune responses, is typically triggered. ${ }^{[3-6]}$ The immunopotential of an LPS is strictly structure-related: there are LPS molecules acting as agonists of TLR4/MD-2 receptorial complex, activating the pro-inflammatory response, whereas others, in a structure dependent fashion, can moderately activate the immune response or can even antagonize the binding of toxic LPS to the immune receptor complex. ${ }^{[3-6]}$ Given the above, the search for new LPS derivatives, that can be used as immunomodulatory compounds in a perspective of drug synthesis and development, is increasingly growing. ${ }^{[7]}$

LPSs consist of three different domains: a glycolipid part, termed lipid $\mathrm{A}$, an oligosaccharide part termed core (core OS) and a highly variable polysaccharide moiety, designated as the $\mathrm{O}$ chain, that is the outermost portion of the macromolecule. ${ }^{[3-7]}$ In the case of absence of the O-chain, the LPS is termed rough-type LPS (R-LPS), whereas when expressing all moieties, is designated as smooth-type LPS (S-LPS). ${ }^{[3-6,8,9]}$ Since the structure of LPS is strongly influenced by the physiological conditions of the surrounding environment, it is reasonable to assume that marine bacteria can colonize a hostile habitat by modifying their LPS structure in order to reinforce the membrane and to assure protection and proliferation. ${ }^{[8]}$ Therefore, LPSs showing unusual chemical characteristics are expected for marine bacteria. Within this frame, LPSs expressing uncommon structural features are taken in consideration as potential antagonists of MD-2/TLR4 receptorial complex. ${ }^{[8,9]}$

The present study is focused on the LPS from Cobetia pacifica $\mathrm{KMM} 3879^{\top}$, a marine bacterium isolated from a sandy sediment (depth $1 \mathrm{~m}$ ) sample collected from the shore of the Sea of Japan (Russia). We have previously established that this bacterium 
expresses an S-LPS with an uncommon O-chain structure made up of a trisaccharide repeating unit containing rhamnose, 3-Osulphate-D-glucose and 3-O-sulphate-D-galactose. ${ }^{[10]}$ Here we describe the structural characterization of the lipid A moiety that turned out to be a complex mixture of variously acylated species. Moreover, a detailed investigation of the C. pacifica KMM $3879^{\top}$ LPS pro-inflammatory activity, on both human and murine cell lines, was performed, clearly demonstrating its weak agonistic activity and its inhibitory effect against potent agonist LPS.

\section{Results and Discussion}

Isolation and fatty acid compositional analysis of the lipid A isolated from C. pacifica KMM $3879^{\top}$ LPS.

The LPS was extracted from dried bacterial pellet through the hot phenol/water procedure. ${ }^{111]}$ The nature and relative purity of the extracted material was established through SDS-PAGE after silver nitrate gel staining ${ }^{[12]}$ which showed a ladder-like profile in the upper part of the gel typical of an S-LPS (Figure S1). ${ }^{[10]}$ To remove cell contaminants, such as proteins and nucleic acids, the extracted LPS was subjected to an extensive enzymatic digestion followed by dialysis and ultracentrifugation. A further step of purification by size-exclusion chromatography was also executed.

A set of chemical analyses, both to determine the sugar and lipid content, was executed on an aliquot of pure LPS. Monosaccharide analysis confirmed the occurrence, as main species, of rhamnose, galactose and glucose, in agreement with our previous data. ${ }^{10]}$ Investigation of the total fatty acid content revealed the occurrence mainly of $(R)$-3-hydroxydodecanoic acid $((R)-12: 0(3-\mathrm{OH}))$, dodecanoic (12:0) and decanoic (10:0) acids. In minor amounts, $(R)$-3-hydroxydecanoic acid $((R)-10: 0(3-\mathrm{OH}))$, $(R)$-3-hydroxyundecanoic acid $((R)-11: 0 \quad(3-\mathrm{OH})), \quad(R)-3-$ hydroxytridecanoic acid $((R)-13: 0(3-\mathrm{OH}))$, undecanoic acid $(11: 0)$ and tridecanoic acid (13:0) were also identified.

\section{MALDI Mass Spectrometry (MS) investigation of the lipid A from C. pacifica KMM $3879^{\top}$ LPS.}

In order to define the lipid A structure in detail, an aliquot of the pure LPS was subjected to a mild acid hydrolysis with acetate buffer, typically used to selectively cleave the labile glyosidic linkage between the core OS and the non-reducing glucosamine of the lipid A domain. In parallel, the lipid A micro-extraction procedure following the El Hamidi et al. approach ${ }^{[13]}$ (referred to here on as micro-extracted lipid A) on lyophilized bacterial pellet was also performed.

A meticulous MALDI MS and MS/MS analysis was executed both on the mild acid hydrolysis product and the micro-extracted lipid A. The reflectron MALDI mass spectrum, recorded in negative polarity, of the micro-extracted lipid $A$ is reported in Figure 1; it showed a complex pattern of peaks relative to deprotonated $[\mathrm{M}-\mathrm{H}]^{-}$lipid A species differing in the number and the nature of fatty acids and in phosphate content. The heterogeneity of $C$. pacifica $\mathrm{KMM} 3879^{\top}$ lipid A structure was visible since most of the main peaks were characterized by the occurrence of mass differences of 28 amu $\left(-\mathrm{CH}_{2} \mathrm{CH}_{2}\right.$ - unit) which are diagnostic for lipid $\mathrm{A}$ species differing in the length of their acyl chains, also in accordance to compositional analysis data. Three distinct sets of peaks around $\mathrm{m} / \mathrm{z} 1628.0,1473.9,1275.7$ were clearly detected (Figure 1) and matched with hexa-acylated, penta-acylated and tetra-acylated lipid A species carrying 12:0 (3$\mathrm{OH}), 12: 0$ and 10:0 as acyl moieties. In detail, the ion at $\mathrm{m} / \mathrm{z}$ 1628.0 was assignable to a bis-phosphorylated hexa-acylated lipid A species carrying four 12:0 (3-OH) units, one 12:0 and one 10:0 fatty acids. The relative mono-phosphorylated lipid $A$ species was also attributed to the peak at $m / z$ 1548.0. In the mass range $\mathrm{m} / \mathrm{z}$ 1349.9-1473.9, penta-acylated lipid A species were identified: the peak at $m / z 1473.9$ matched with a bis-phosphorylated pentaacylated lipid A form carrying four 12:0 $(3-\mathrm{OH})$ residues and one $12: 0$; the peak at $m / z 1429.9$ was assignable to a different pentaacylated lipid $A$ species decorated by two phosphate groups and carrying three 12:0 (3-OH) units, one 12:0 and one 10:0. The corresponding mono-phosphorylated penta-acylated forms were also present at $m / z 1393.9$ and 1349.9 respectively. Finally, tetraacylated lipid A species, mono- or bis-phosphorylated, lacking one 12:0 (3-OH) with the respect to penta-acylated species $(\mathrm{m} / \mathrm{z}$ 1473.9), were also detected.

The negative-ion MALDI mass spectrum of the product isolated by mild acid treatment (not shown) appeared identical to that achieved by the micro-extraction procedure. A detailed negativeion MS/MS analysis on several ion peaks of the mild acid treatment product was performed to unveil the location of the lipid A acyl moieties with respect to the glucosamine disaccharide backbone. In detail, MS/MS spectrum of the precursor ion at $\mathrm{m} / \mathrm{z}$ 1628.0 (Figure 2), relative to the bis-phosphorylated hexaacylated species, clearly showed an intense peak at $m / z 1411.9$ corresponding to an ion originated from the loss of a 12:0 $(3-\mathrm{OH})$ fatty acid. A further intense peak, at $m / z 1313.9$, was assigned to a fragment lacking both one phosphate unit and one 12:0 $(3-\mathrm{OH})$ fatty acid. Less intense peaks were also observed at $m / z 1427.9$ and 1211.8 and were assigned to fragments originated from the loss of a $12: 0$ fatty acid $(\mathrm{m} / \mathrm{z} 1427.9)$ and both of one $12: 0(3-\mathrm{OH})$ and one $12: 0(\mathrm{~m} / z 1211.8)$ fatty acids. The presence of the last peak and the concurrent absence of peaks corresponding to fragments originated from a loss of a hydroxylated fatty acid bearing a secondary acyl substituent indicates that secondary fatty acids are linked to the acyloxyacyl amides. The ion originating from the cleavage of the glycosydic linkage of the glucosamine backbone $\left(Y_{1}\right)^{[14]}$ was pivotal to confirm the acyl chains distribution with the respect to the disaccharide backbone. Indeed, peak at $m / z 808.5$ was crucial to prove that the 10:0 unit was a secondary acyl substituent decorating only the reducing glucosamine which also carried two 12:0 (3-OH) moieties and one phosphate. The MS/MS analysis of the precursor ion at $\mathrm{m} / \mathrm{z}$ 1473.9 (Figure S2) confirmed the assignment to a bisphosphorylated penta-acylated lipid A species expressing four $12: 0(3-\mathrm{OH})$ as primary fatty acids, and one 12:0 as secondary acyl substituent; this hypothesis was supported by the occurrence of the product ions at $\mathrm{m} / \mathrm{z} 1257.7$ and 1274.7 corresponding to lipid A fragments produced from the loss of one 12:0 $(3-\mathrm{OH})$ and one 12:0 fatty acid, respectively (Figure S2). The fragment ion observed at $\mathrm{m} / \mathrm{z} 1159.7$ was correlated to a fragment devoid of 
both one phosphate and one 12:0 (3-OH) fatty acid. Interestingly, besides the above mentioned $Y_{1}$ ion $(\mathrm{m} / \mathrm{z} 654.3)$, a further peak, originating from the sugar ring fragmentation $\left({ }^{0,4} A_{2}\right)^{[14]}$ at $\mathrm{m} / \mathrm{z}$ 878.5, was also detected. Both $Y_{1}$ and ${ }^{0,4} A_{2}$ ions were again fundamental to confirm the fatty acids distribution with the respect to the glucosamine backbone. In particular, the ${ }^{0,4} \mathrm{~A}_{2}$ ion was crucial not only to confirm the nature of the primary acyl chains decorating the reducing glucosamine unit (namely two 12:0 (3$\mathrm{OH})$ ) but also to clearly locate the secondary acyl chain 12:0 at the non-reducing glucosamine unit. Finally, the negative-ion MS/MS spectrum of the precursor ion at $m / z 1275.7$ (Figure 3), relative to a bis-phosphorylated lipid A species carrying three 12:0 $(3-\mathrm{OH})$ and one 12:0, showed peaks at $\mathrm{m} / \mathrm{z} 1075.5,1059.5$ and 961.5 relative to lipid $A$ fragments devoid of one 12:0 ( $\mathrm{m} / \mathrm{z}$ 1075.5) one 12:0 (3-OH) $(\mathrm{m} / \mathrm{z}$ 1059.5), one 12:0 (3-OH) and one phosphate unit $(\mathrm{m} / \mathrm{z} 961.5)$. Moreover, it showed the important peak at $\mathrm{m} / z 654.3$ corresponding to the $Y_{1}$ ion that, as previously mentioned, confirmed that the reducing glucosamine carries two 12:0 $(3-\mathrm{OH})$ residues.

In order to unequivocally establish the secondary fatty acids composition and position, an aliquot of lipid A was subjected to ammonium hydroxide hydrolysis. ${ }^{[15]}$ The MALDI mass spectrum (Figure 4), recorded in negative polarity, of the ammonium treated lipid A showed ion peaks in the $m / z$ range of 997.6-1349.4 that could be assigned as follows: the ion at $m / z 1151.7$ was explained as a mono-phosphorylated tetra-acyl residue made up of both the primary amide-linked 12:0 $(3-\mathrm{OH})$ carrying the secondary 10:0 and 12:0 units; the ion at $\mathrm{m} / \mathrm{z} 997.6$ was identified as the monophosphorylated tri-acyl residue composed of the $N$-linked 12:0 (3$\mathrm{OH}$ ) units and one 12:0 (Figure 4). Minor peaks at $\mathrm{m} / \mathrm{z} 1195.7$ and 1275.7 were assigned to mono-phosphorylated $(\mathrm{m} / \mathrm{z} 1195.7)$ and bis-phosphorylated $(\mathrm{m} / \mathrm{z}$ 1275.7) tetra-acyl lipid $A$ made up of three 12:0 (3:OH) and one 12:0. Similarly, peak at $\mathrm{m} / \mathrm{z} 1231.6$ was identified as the bis-phosphorylated tetra-acyl residue composed of the two amide-linked 12:0 $(3-\mathrm{OH})$ units carrying the $10: 0$ and 12:0 secondary acyl substituents, whereas peak at $\mathrm{m} / \mathrm{z} 1349.8$ accounted for the mono-phosphorylated penta-acylated form decorated by three 12:0 (3-OH), one 10:0 and 12:0. The negative ion MS/MS analysis of precursor ions at $\mathrm{m} / \mathrm{z} 1151.7$ and 997.6 univocally established the location of the secondary acyl substituents (Figures 5 and S3). Briefly, the MS/MS spectrum of precursor ion at $\mathrm{m} / \mathrm{z} 1151.7$ (Figure 5) clearly showed ions at $\mathrm{m} / \mathrm{z}$ 951.6 and 979.6 relative to lipid $A$ fragments devoid of $12: 0$ and 10:0 fatty acid respectively. More interestingly, ions ${ }^{0,2} A_{2}$ and ${ }^{0,2} A_{1}$ at $m / z 740.4$ and 200.0, respectively, proved the exact location of the secondary acyl substitution 12:0 as occurring exclusively on the primary amide-bound fatty acid of the non-reducing glucosamine. This specularly further proved the nature of the 10:0 as the secondary fatty acid of the acyloxyacyl amide moiety of the reducing glucosamine. This structural assignment was further confirmed by the negative-ion MS/MS analysis of the precursor ion at $m / z 997.6$ whose spectrum is reported in Figure S3.

Thus, by merging MS and MS/MS data of the micro-extracted lipid $A$, the mild acid hydrolysis and the ammonium hydroxide-treated products with the compositional analysis, it was possible to define the C. pacifica KMM $3879^{\top}$ LPS as expressing a complex blend of lipid A species whose component with the highest acylation degree is shown in Figure 6. The anomeric configuration of both glucosamine units was not determined and is sketched in Figure 6 as following literature data on previously characterized lipid $A$ structures.

\section{Immunological properties of $C$. pacifica KMM $3879^{\top}$ LPS.}

We examined the effect of $C$. pacifica KMM $3879^{\top}$ LPS on both the human and murine innate immune system in vitro.

First, we tested the immunopotential of $C$. pacifica KMM $3879^{\top}$ LPS through its analysis in mouse (C57BL/6) bone marrow derived macrophages (BMDMs). BMDMs were exposed to different $C$. pacifica KMM $3879^{\top}$ LPS concentrations (1, 10, and $100 \mathrm{ng} / \mathrm{mL}$ ) for $6 \mathrm{~h}$. The potent agonist LPS from E. coli O111:B4 was used as a positive control in parallel, as above. Unstimulated cells were as negative control. The measurement of the release of Tumor necrosis factor- $\alpha$ (TNF- $\alpha$ ) was the read-out of this experiment. As shown in Figure 7a, the C. pacifica KMM 3879 LPS caused a lower release of TNF- $\alpha$ compared to $E$. coli LPS ( $C$. pacifica KMM $3879^{\top}$ LPS vs. E. coli LPS $p<0.05$ at $100 \mathrm{ng} / \mathrm{mL} ; p$ $<0.01$ at $1 \mathrm{ng} / \mathrm{mL} ; p<0.001$ at $10 \mathrm{ng} / \mathrm{mL}$ ), thus indicating a weak capability to elicit an inflammatory response in murine macrophages.

Since it is known that the human TLR4/MD-2 complex is more sensitive to detect and discriminate among the different LPS species than the murine TLR4/MD-2, to establish whether human monocytes are more sensitive than BMDMs to $C$. pacifica KMM $3879^{\top}$ LPS, we used human peripheral blood mononuclear cells (PBMC) in a stimulation assay. Cells were stimulated for $18 \mathrm{~h}$ with LPS of C. pacifica KMM $3879^{\top}$ at concentrations of $10 \mathrm{ng} / \mathrm{mL}, 1$ $\mathrm{ug} / \mathrm{mL}$ and $10 \mathrm{ug} / \mathrm{mL}$ or $E$. coli O111:B4 at concentrations of 1, 10 and $100 \mathrm{ng} / \mathrm{mL}$. As above, release of the inflammatory cytokine TNF- $\alpha$ was quantified. Low amounts of TNF- $\alpha$ were detected with the LPS of $C$. pacifica KMM $3879^{\top}$, whereas LPS of $E$. coli induced a significantly high release of this cytokine (C. pacifica KMM $3879^{\top}$ LPS vs. E. coli LPS $p<0.01$ at $10 \mu \mathrm{g} / \mathrm{mL} ; p<0.001$ at $100 \mathrm{ng} / \mathrm{mL}$ and $1 \mu \mathrm{g} / \mathrm{mL}$ ) (Figure $7 \mathrm{~b}$ ).

The low immunological properties of $C$. pacifica KMM $3879^{\top}$ LPS were also assessed in the model of HEK293 cells stably expressing human CD14, MD-2, and human TLR4. HEK 293 hTLR4 cells were stimulated with different $C$. pacifica KMM $3879^{\top}$ LPS concentrations $(1,10$, and $100 \mathrm{ng} / \mathrm{mL}$ ). Likewise, the LPS from $E$. coli $\mathrm{O} 111: \mathrm{B} 4$ was employed at the same concentrations. Activation of NF-KB (Nuclear Factor kappa B) and CXCL-8 (Chemokine ligand 8) production were the read-out of this experiment. The luciferase assay results showed that the $C$. pacifica KMM $3879^{\top}$ LPS induced a significantly lower NF-KB activation with respect to cells treated with E. coli LPS (C. pacifica KMM $3879^{\top}$ LPS vs. E. coli LPS $p<0.01$ at $10 \mathrm{ng} / \mathrm{mL} ; p<0.001$ at $1 \mathrm{ng} / \mathrm{mL}$ and $100 \mathrm{ng} / \mathrm{mL}$ ) (Figure $8 \mathrm{a}$ ). In accordance with this result, CXCL-8 production was lower after stimulation with $C$. pacifica KMM $3879^{\top}$ LPS with respect to LPS from E. coli LPS ( $C$. pacifica KMM $3879^{\top}$ LPS vs. E. coli LPS $p<0.01$ at $1 \mathrm{ng} / \mathrm{mL} ; p<$ 0.001 at $10 \mathrm{ng} / \mathrm{mL}$ and $100 \mathrm{ng} / \mathrm{mL}$ ) (Figure $8 b$ ).

Since some LPS isolated from marine bacteria have been reported to exhibit a fascinating potential as inhibitors of endotoxically active LPS, we next proceeded to evaluate the 
ability of $C$. pacifica KMM $3879^{\top}$ LPS to interfere with the TLR4mediated signaling triggered by $E$. coli LPS. To assess this capability, HEK 293-hTLR4 cells were pre-incubated for $1 \mathrm{~h}$ with different amounts $(1,10$, and $100 \mathrm{ng} / \mathrm{mL})$ of C. pacifica KMM $3879^{\top}$ LPS and then exposed to $10 \mathrm{ng} / \mathrm{mL}$ of $E$. coli LPS for $4 \mathrm{~h}$ (Figure 9). NF-KB activation and CXCL-8 production were the read-out of this experiment. The results clearly showed that $C$. pacifica KMM $3879^{\top}$ LPS significantly inhibited $E$. coli LPSdependent TLR4-mediated NF-KB activation as well as CXCL-8 production at all the concentrations tested (NF-KB activation, $C$. pacifica KMM $3879^{\top}$ LPS vs. E. coli LPS $p<0.01$ at $10 \mathrm{ng} / \mathrm{mL}$ and $100 \mathrm{ng} / \mathrm{mL} ; p<0.001$ at $1 \mathrm{ng} / \mathrm{mL} ; C X C L-8$ production, $C$. pacifica $\mathrm{KMM} 3879^{\top}$ LPS vs. E. coli LPS $p<0.001$ at $1 \mathrm{ng} / \mathrm{mL}$ ). Interestingly, when HEK 293-hTLR4 cells were pre-incubated with the lowest concentration of $C$. pacifica KMM $3879^{\top}$ LPS $(1 \mathrm{ng} / \mathrm{mL})$ and then exposed to $10 \mathrm{ng} / \mathrm{mL}$ of $E$. coli LPS, the inhibitory activity of the marine bacterium LPS resulted in higher measurements for both the NF-KB and CXCL-8 levels.

A similar competition assay, by stimulating PBMC with different amounts $(100 \mathrm{ng} / \mathrm{mL}, 1$ and $10 \mu \mathrm{g} / \mathrm{mL})$ of $C$. pacifica KMM $3879^{\top}$ LPS and then exposed to $10 \mathrm{ng} / \mathrm{mL}$ of $E$. coli LPS, was also performed (Figure S4). The latter competition assay further confirmed the inhibitory properties of $C$. pacifica KMM $3879^{\top}$ LPS with regards to the $E$. coli LPS toxicity on human macrophages.

All these data clearly suggest that $C$. pacifica KMM $3879^{\top}$ LPS acts as a very weak immunostimulant agent on both human and murine immune cells. Intriguingly, it also exhibits a good TLR4/MD-2 inhibitory activity towards the potent agonist LPS at all the concentrations used in the assays.

\section{Conclusions}

Marine bacteria represent a basin of biodiversity able to furnish intriguing biological activities to be investigated. The hostile environmental conditions that marine bacteria face render them a promising source of human non-toxic compounds that can be potentially used for clinical applications. ${ }^{[7]}$ Within this frame, several potential therapeutics based on modified LPSs have entered clinical trials to examine their ability to reduce inflammatory LPS-triggered symptoms. ${ }^{[16,17]}$ The observation of very weak or no immunostimulatory effects exerted by some LPSs isolated from marine bacteria, in addition to the never-ending reservoir from which such microorganisms can be isolated, indubitably make them potential targets to employ for bio-inspired therapies against LPS-induced sepsis and septic shock. ${ }^{[8,16]}$ In view of this, here we showed the structural characterization of the lipid A isolated from the marine bacterium C. pacifica KMM $3879^{\top}$ LPS, executed by MALDI MS and MS/MS investigation on the lipid $A$ directly isolated from cells through the El Hamidi et al protocol, ${ }^{[12]}$ and on the lipid $A$ obtained after mild acid treatment on the pure LPS..

The C. pacifica KMM $3879^{\top}$ LPS exhibited a heterogenous lipid A with penta-acylated species as the main forms, decorated by one or two phosphate groups. Briefly, two penta-acylated species have been detected, differing in the acylation pattern: i) one lipid A species was constituted by four $(R)-12: 0(3-\mathrm{OH})$ and one 12:0, ii) whereas the other was decorated by three $(R)-12: 0(3-\mathrm{OH})$, one
10:0 and one 12:0. In addition to such heterogeneity, a further variability in the fatty acid chain length for each species has been observed. Hexa-acylated lipid A species carrying a further secondary acyl chain, as well as tetra-acylated forms were also detected. Therefore, the structural elucidation further confirmed the general tendency of marine bacteria lipid As to express shorter acyl chains [10:0, 12:0, $12.0(3-\mathrm{OH})]$ with respect to those isolated from other bacterial strains, like Enterobacteriaceae. ${ }^{[8]}$ This shortening of the lipid A acyl chains can be considered as an evolutionary adaptation stratagem of the bacterial cell envelope to resist to environmental stress factors, since short lipids have less Van der Waals interactions between the chains, compared to long chain fatty acids, thus preserving the required fluidity of the membrane to survive in the variable marine habitat. ${ }^{[8,10]}$ Analogously, the sulfate groups decorating the O-chain structure of $C$. pacifica KMM $3879^{\top}$ might act as a buffering system to regulate the $\mathrm{pH}$ on the external membrane surface, thus providing protection to the bacterium against the environmental salinity conditions. ${ }^{[8,10]}$

The establishment of the structure of the lipid A from C. pacifica KMM $3879^{\top}$ prompted us to screen its immunological properties on TLR4/MD-2 complex both in human and murine systems. The immunological studies clearly demonstrated the very weak capability of $C$. pacifica KMM $3879^{\top}$ LPS in eliciting an immune response, as shown by the significantly low release of proinflammatory cytokines in murine BMDMs and upon human TLR4 complex stimulation. These results are intriguing since $C$. pacifica KMM $3879^{\top}$ LPS was composed of a mixture of tetra-, penta-, and even hexa-acylated lipid A species with this latter form considered as the typical immunostimulant ligand of the TLR4/MD-2 complex. Notwithstanding, evident structural differences between $E$. coli LPS and C. pacifica KMM $3879^{\top}$ LPS may be responsible for the different immunological properties observed. Indeed, the presence of acyl chains shorter than those of E. coli (10 and 12 carbon atoms vs. 14 and 12 carbon atoms) as well as the symmetric distribution of the acyl moieties of $C$. pacifica KMM $3879^{\top}$ lipid $A(3+3$ symmetry, in its hexa-acylated form, vs. 4+2 symmetry of $E$. coli lipid A) can be considered at the basis of the weak capability of $C$. pacifica KMM $3879^{\top}$ LPS to engage the TLR4/MD-2/CD14 pathway. Even more appealing was the observation of the potent inhibitory activity exhibited by $C$. pacifica KMM $3879^{\top}$ LPS towards the toxic effects of $E$. coli LPS on the human TLR4/MD-2 complex. This fascinating property has been extensively reported for tetra-acylated lipid $A$, such as lipid $I V_{A},{ }^{[18]}$ and also for some other marine bacteria such as Halomonas megadiensis ${ }^{[19]}$ and Halobacteroides lacunaris ${ }^{[20]}$ as well as for the thermophilic bacterium Thermomonas hydrothermalis. ${ }^{[21]}$ The TLR4/MD-2 inhibitory action of $C$. pacifica KMM $3879^{\top}$ LPS may be justified by the occurrence of hypo-acylated lipid A species, namely tetra- and penta-acylated, in addition to the hexa-acylated forms, thus resulting in a very weak elicitation of an immune response but maintaining the capability to robustly compete with the toxic E. coli LPS for binding to the TLR4/MD-2 complex.

In summary, this work certainly confirmed that, besides the peculiar structural features of $C$. pacifica KMM $3879^{\top}$ LPS, the exploration of marine bacteria LPS is a fundamental choice to screen for lipid A structures that may be of inspiration for 
developing analogues with an immunomodulatory action on the immune system.

\section{Experimental Section}

\section{Bacteria Isolation and Growth}

Bacteria were isolated from a sandy sediment sample collected at a depth of $1 \mathrm{~m}$ from the shore of the Sea of Japan, Russia. The bacterium was cultivated for $48 \mathrm{~h}$ at ambient temperature on the medium consisting of $\left(\mathrm{L}^{-1}\right): 5.0 \mathrm{~g}$ bactopeptone, $2.5 \mathrm{~g}$ yeast extract, $1.0 \mathrm{~g}$ glucose, $0.2 \mathrm{~g}$ $\mathrm{K}_{2} \mathrm{HPO}_{4}, 0.05 \mathrm{~g} \mathrm{MgSO}_{4}$, and $750 \mathrm{~mL}$ natural seawater $/ 250 \mathrm{~mL}$ distilled water.

\section{Extraction and purification of the LPS from C. pacifica KMM 3879}

Dried cells were extracted by the hot phenol/water procedure ${ }^{[11]}$ and the extracted material was dialyzed against distilled water. The nature of the extracted material was screened by an SDS - PAGE followed by silver nitrate gel staining ${ }^{[12]}$ that confirmed the smooth nature of the isolated LPS. To remove cell contaminants, such as proteins and nucleic acids, an enzymatic treatment with RNase (Sigma-Aldrich, Darmstadt, Germany), DNase (Sigma-Aldrich, Darmstadt, Germany), and Proteinase K (SigmaAldrich, Darmstadt, Germany) $\left(37^{\circ} \mathrm{C}\right.$ and $\left.56^{\circ} \mathrm{C}\right)$ was executed, followed by exhaustive dialysis against distilled water. Further steps of purification were executed, namely an ultracentrifugation $\left(4{ }^{\circ} \mathrm{C}, 100,000 \times g, 16 \mathrm{~h}\right)$ and a size-exclusion chromatography on a Sephacryl High Resolution S300 (GE Healthcare, Little Chalfont, UK) column.

\section{Chemical analyses}

The monosaccharide content was established by analysis of the acetylated $O$-methyl glycoside derivatives obtained by treatment with $\mathrm{HCl} / \mathrm{MeOH}\left(1.25 \mathrm{M}, 85^{\circ} \mathrm{C}\right)$ followed by acetylation with acetic anhydride in pyridine $\left(85^{\circ} \mathrm{C}, 30 \mathrm{~min}\right) .^{[22]}$ The total fatty acid content was defined on intact LPS after hydrolysis with $\mathrm{HCl}\left(4 \mathrm{M}, 100{ }^{\circ} \mathrm{C}, 4 \mathrm{~h}\right)$ followed by a neutralization step with $\mathrm{NaOH}\left(5 \mathrm{M}, 100{ }^{\circ} \mathrm{C}, 30 \mathrm{~min}\right)$. The fatty acids were extracted in chloroform and then methylated with diazomethane. The absolute configuration of acyl chains was determined as previously described. ${ }^{[23]}$ Authentic 3-hydroxy fatty acids were used to assign the $(R)$ configuration to the LPS fatty acids. The obtained derivatives of sugars and fatty acids were analyzed by means of gas-liquid chromatography (GLC-MS) Agilent Technologies 6850A (Santa Clara, CA, USA) equipped with a mass selective detector $5973 \mathrm{~N}$ and a Zebron ZB - 5 capillary column (Phenomenex, $30 \mathrm{~m} \times 0.25 \mathrm{~mm}$ i.d., $0.25 \mu \mathrm{m}$ as film thickness, flow rate $1 \mathrm{~mL} / \mathrm{min}$, He as carrier gas) and using the temperature program $140{ }^{\circ} \mathrm{C}$ for $3 \mathrm{~min}, 140^{\circ} \mathrm{C} / 240^{\circ} \mathrm{C}$ at $3^{\circ} \mathrm{C} / \mathrm{min}$.

\section{Isolation of the lipid A fraction from C. pacifica KMM $3879^{\top}$ LPS}

In order to study the lipid A structure, an aliquot $(30 \mathrm{mg})$ of pure LPS underwent a treatment with acetate buffer $\left(\mathrm{pH} \mathrm{4.4)}\right.$ for $3 \mathrm{~h}$ at $100^{\circ} \mathrm{C}$ under magnetic stirring. A mixture of chloroform and methanol was added to the hydrolysate to reach a chloroform/ methanol/hydrolysate 2:2:1.8 ( $/ / \mathrm{v} / \mathrm{v})$ ratio. The mixture was then shaken and centrifuged. The chloroform phase containing the lipid A fraction, was collected and washed with the water phase of a freshly prepared Bligh/Dyer mixture (chloroform/ methanol/water, 2:2:1.8). ${ }^{[24]}$ The organic phases were pooled, dried and analyzed by MALDI MS.
Finally, an aliquot of the pure lipid $\mathrm{A}$ was also treated with $10 \% \mathrm{NH}_{4} \mathrm{OH}$ as previously described and analyzed by MALDI MS. ${ }^{[15]}$

An aliquot of bacterial pellet underwent the lipid A micro-extraction procedure as previously reported. [13]

\section{MALDI mass spectrometry}

Micro-extracted lipid A was analyzed on a AB SCIEX TOF/TOFTM 5800 Applied Biosystems mass spectrometer. All others MALDI MS and MS/MS spectra were executed on a 4800 Proteomic analyzer (SCIEX, Concord, ON, Canada) supplied with a Nd:YAG laser (wavelength of $355 \mathrm{~nm}$ ). Lipid A preparations were performed as previously described. ${ }^{[25,26,27]}$ Briefly, the sample was dissolved in $\mathrm{CHCl}_{3} / \mathrm{CH}_{3} \mathrm{OH}(50: 50 \mathrm{v} / \mathrm{v})$ whereas the matrix solution was trihydroxyacetophenone (THAP) dissolved in $\mathrm{CH}_{3} \mathrm{OH} / 0.1 \%$ $\mathrm{TFA} / \mathrm{CH}_{3} \mathrm{CN}(7: 2: 1 \mathrm{v} / \mathrm{v} / \mathrm{v})$ at a concentration of $75 \mathrm{mg} / \mathrm{mL}$. The ammonium hydroxide treated lipid $A$ was prepared as previously described. ${ }^{[15]} \mathrm{A}$ sample/matrix solution mixture $(1: 1 \mathrm{v} / \mathrm{v})$ was deposited $(1 \mu \mathrm{L})$ onto a $100-$ sample MALDI probe tip, and left to dry at room temperature. Mass accuracy was found below 75 ppm. 2000 laser shots were approximately accumulated for each mass spectrum, whereas 4000/6000 shots were summed for MS/MS acquisitions.

\section{BMDMs isolation, culture and stimulation}

C57BL/6 mice were purchased from Charles River (Charles River ITALY) BMDMs were derived from the bone marrow cells collected from five-week old female mice, as already reported. ${ }^{[28]}$ Animal studies were conducted according to protocols approved by the University of Rome La Sapienza and adhered strictly to the Italian Ministry of Health guidelines for the use and care of experimental animals. Subsequently, BMDMs were differentiated during 5 days in RPMI1640 (Lonza, Italy), supplemented with $10 \%$ FBS (Hyclone, U.S.), $1 \%$ Glutamine (Lonza, Italy), $1 \%$ Na pyruvate (Lonza, Italy), 1 \% NEAA (Lonza, italy), 0.5 \% 2-ME (Gibco, Italy), and 30 $\mathrm{ng} / \mathrm{mL}$ macrophage colony-stimulating factor (M-CSF; Miltenyi Biotec). For the stimulation assay BMDMs were seeded into 24-well plates $\left(5 \times 10^{5}\right.$ cells per well) and were exposed to different concentrations of $C$. pacifica KMM $3879^{\top}$ or E. coli LPS O111:B4 (1, 10, or $100 \mathrm{ng} / \mathrm{mL}$ ) (INVIVOGEN) for $18 \mathrm{~h}$. After this time the supernatant was removed and the level of TNFa measured through ELISA

\section{Human PMBCs differentiation and stimulation}

PBMCs were isolated from buffy coats obtained by the blood bank of Sapienza University from healthy adult volunteers (blood donors) following written informed consent. PBMC were obtained through a density gradient. CD14 ${ }^{+}$monocytes were isolated using the MACS microbead system (Miltenyi Biotec, Bergisch Gladbach, Germany). The monocytes were cultured for 6 days in RPMI 1640 (Lonza) supplemented with $10 \%$ heatinactivated FBS (Euroclone Fetal Bovine Serum, GE Healthcare Life Sciences,U.S.), $100 \mu \mathrm{M}$ non-essential amino acids, $1 \mathrm{mM}$ sodium pyruvate, $1000 \mathrm{U} / \mathrm{ml}$ penicillin and $1000 \mathrm{U} / \mathrm{mL}$ streptomycin (all from Lonza, Italy). For LPS stimulation the cells were seeded in 24-well plates $\left(2,5 \times 10^{5}\right.$ cells/well, exposed to 1,10 or $100 \mathrm{ng} / \mathrm{mL}$ of LPS derived from C. pacifica KMM $3879^{\top}$ or commercial E. coli O111:B4 for $18 \mathrm{~h}$. Cell supernatants were recovered and processed for ELISA. For the competition assays, PBMCs cells were exposed to LPS $(1,10$ and $100 \mathrm{ng} / \mathrm{mL})$ of $C$. pacifica KMM $3879^{\top}$ together with $10 \mathrm{ng} / \mathrm{mL}$ of $E$. coli LPS for 18 hours. After this time, TNF- $\alpha$ production was measured.

\section{Cytokine measurement}


Murine and human TNF- $\alpha$ and human CXCL-8 were determined in supernatants of stimulated BMDMs by using R\&D Systems DuoSet ELISA kits according to the manufacturers' instructions.

\section{Cell cultures}

The stably transfected human embryonic kidney epithelial cell line HEK 293-hTLR4/MD2-CD14 (InvivoGen) were cultured in DMEM with $10 \%$ FBS (Eurclone), $10 \mu \mathrm{g} / \mathrm{mL}$ Blasticidin-S and $50 \mu \mathrm{g} / \mathrm{ml}$ HygroGold® (both by InvivoGen).

HEK 293-hTLR4/CD14/MD2 cell culture, transfection and stimulation Stably transfected cell line HEK 293-hTLR4/MD2-CD14 were seeded into 96-well plates at the concentration of $1 \times 10^{5} \mathrm{cell} / \mathrm{s} / \mathrm{mL}$. The next day cells were transiently transfected with PolyFect Transfection Reagent (Qiagen) with a reaction mix composed by $150 \mathrm{ng}$ of Firefly luciferase reporter constructs, pGL3.ELAM.tk (containing NF-KB promoter sequences), and $15 \mathrm{ng}$ of Renilla luciferase reporter plasmid, pRLTK (as an internal control). Twenty-four hours post-transfection cells were untreated or incubated with different concentrations $(1,10$ and $100 \mathrm{ng} / \mathrm{mL})$ of LPS of $C$. pacifica KMM $3879^{\top}$ or of purified E. coli LPS (LPS-EB ultrapure; InvivoGen) for $6 \mathrm{~h}$ to analyze NF-KB activity and to measure CXCL-8 release. For the competition assays, HEK 293-TLR4/MD2-CD14 cells were primed with LPS $\left(1,10\right.$ and $100 \mathrm{ng} / \mathrm{mL}$ ) of $C$. pacifica KMM $3879^{\top}$ for 1 hour and then stimulated with $10 \mathrm{ng}$ of $E$. coli LPS for 4 hours. After this time, NF-KB activity and CXCL-8 production were measured.

\section{Acknowledgements}

AM and AS acknowledge H2020-MSCA-ITN-ETN project $n$. 642157 "Tollerant". AS acknowledges "PNRA Programma Nazionale di Ricerca in Antartide 2016“. The reported study was partially funded by RFBR according to the research project № 18004-00618.

Keywords: Marine bacteria $\cdot$ Cobetia $\cdot$ Lipopolysaccharide (LPS) $\bullet$ Innate Immunity $\bullet$ MD-2/TLR4 inhibitors

[1] L. J. Rothschild, R. L. Mancinelli, Nature 2001, 409, 1092-1100.

[2] S. Leone, A. Silipo, E. L. Nazarenko, R. Lanzetta, M. Parrilli, A. Molinaro, Mar. Drugs 2007, 5, 85-112.

[3] C. Alexander, E.T. Rietschel, J. Endotoxin Res. 2001, 7, 167-202.

[4] A. Silipo, C. De Castro, R. Lanzetta, M. Parrilli, A. Molinaro in Prokaryotic Cell Wall Compounds: Structure and Biochemistry, (Eds.: H. Kçnig, H. Claus, H., A. Varma), Springer, Heidelberg, 2010, pp. $133-154$.

[5] F. Di Lorenzo, C. De Castro, R. Lanzetta, M. Parrilli, A. Silipo, A. Molinaro in Carbohydrates in Drug Design and Discovery, Vol. 43, (Eds.: J. Jimenez-Barbero, F. Javier Canada, S. Martín-Santamaría), RSC Drug Discovery Series, 2015, pp. 38-63.

[6] M. Triantafilou, K. Triantafilou, Trends Immunol. 2002, 23, 301-304.
[7] C. De Castro, R. Lanzetta, S. Leone, M. Parrilli, A. Molinaro, Carbohydr. Res. 2013, 370, 9-12.

[8] F. Di Lorenzo, J.-M. Billod, S. Martín Santamaría, A. Silipo, A. Molinaro, Eur. J. Org. Chem. 2017, 4055-4073.

[9] C. R. Raetz, Annu. Rev. Biochem. 1990, 59, 129-170.

[10] M. S. Kokoulin, A. I. Kalinovsky, N. A. Komandrova, S. V. Tomshich, L. A. Romanenko, V. E. Vaskovsky, Carbohydr. Res. 2014, 387, 4-9.

[11] O. Westphal, K. Jann, Methods Carbohydr. Chem. 1965, 1, 83-91.

[12] R. Kittelberger, F. Hilbink, J. Biochem. Biophys. Methods 1993, 26, 8186.

[13] A. El Hamidi, A. Tirsoaga, A. Novikov, A. Hussein, M. Caroff, J. Lipid Res. 2005, 46(8), 1773-8.

[14] B. Domon, C. E. Costello, Glycoconj. J. 1988, 5, 397.

[15] A. Silipo, R. Lanzetta, A. Amoresano, M. Parrilli, A. Molinaro, J. Lip. Res. 2002, 43, 2188.

[16] H. M. Kim, B. S. Park, J. I. Kim, S. E. Kim, J. Lee, S. C. Oh, P. Enkhbayar N. Matsushima, H. Lee, O. J. Yoo, J. O. Lee, Cell 2007, 130(5), 906-17.

[17] R. Nijland, T. Hofland, J. A. G. van Strijp, Mar. Drugs 2014, 12, 42604273.

[18] U. Ohto, K. Fukase, K. Miyake, Y. Satow, Science 2007, 316(5831) $1632-1634$.

[19] A. Ialenti, P. Di Meglio, G. Grassia, P. Maffia M., Di Rosa, R. Lanzetta A. Molinaro, A. Silipo, W. D. Grant, A. Ianaro, Eur. J. Immunol. 2006, 36(2), 354-360.

[20] F. Di Lorenzo, A. Palmigiano, I. Paciello, M. Pallach, D. Garozzo, M.-L. Bernardini, V. La Cono, M. M. Yakimov, A. Molinaro, A. Silipo, Mar Drugs 2017, 15, 201.

[21] F. Di Lorenzo, I. Paciello, L. L. Fazio, L. Albuquerque, L. Sturiale, M. S da Costa, R. Lanzetta, M. Parrilli, D. Garozzo, M. L. Bernardini, A. Silipo, A. Molinaro, ChemBioChem 2014, 15(14), 2146-2155.

[22] K. Leontein, B. Lindberg, J.Lönngren, Methods Carbohydr. Chem. 1978 62, 359-362.

[23] E. T. Rietschel, Eur. J. Biochem. 1976, 64, 423-428.

[24] E. G. Bligh, W. J. Dyer, Can. J. Biochem. Physiol. 1959, 37, 911-917.

[25] A. Silipo, S. Leone, A. Molinaro, R. Lanzetta, M. Parrilli, Carbohydr. Res. 2004, 339, 2241-2248.

[26] A. Silipo, L. Sturiale, D. Garozzo, C. De Castro, R. Lanzetta, M. Parrilli, W. D. Grant, A. Molinaro, Eur. J. Org. Chem. 2004, 2263-2271.

[27] F. Di Lorenzo, Ant. Van Leeuwen. 2017, 110(11), 1401-1412.

[28] F. Saccheri, C. Pozzi, F. Avogadri, S. Barozzi, M. Faretta, P. Fusi, M. Rescigno, Sci. Transl. Med. 2010, 2(44), 44ra57. 


\section{WILEY-VCH}

\section{FULLPAPER}

\section{Figure Legends}

Figure 1. Reflectron MALDI mass spectrum, recorded in negative polarity, of the micro-extracted lipid A from $C$. pacifica KMM $3879^{\top}$ LPS. Only deprotonated ions $[\mathrm{M}-\mathrm{H}]^{-}$are formed in these conditions. The lipid A species are indicated.

Figure 2. MALDI MS/MS spectrum of the hexa-acylated lipid A species at $m / z 1628.0$ from C. pacifica KMM $3879^{\top}$ LPS. Fragment assignments are reported. The proposed structure for the hexa-acylated lipid A species is reported in the inset.

Figure 3. MALDI MS/MS spectrum of the tetra-acylated lipid A species at $m / z 1275.7$ from C. pacifica KMM $3879^{\top}$ LPS. Fragment assignments are reported. The proposed structures for the tetra-acylated lipid A species is reported in the inset.

Figure 4. Negative ion MALDI mass spectrum of the lipid A from C. pacifica KMM $3879^{\top}$ LPS obtained from $10 \%$ $\mathrm{NH}_{4} \mathrm{OH}$ hydrolysis. The proposed structures of the product are reported in the figure.

Figure 5. MALDI MS/MS spectrum of tetra-acylated lipid A species at $\mathrm{m} / \mathrm{z} 1151.7$ from ammonium-hydroxide treated C. pacifica KMM $3879^{\top}$ lipid A.

Figure 6. The proposed structure of the hexa-acylated lipid A species from C. pacifica KMM 3879' LPS.

Figure 7. TNF- $\alpha$ release in macrophages stimulated with LPS of $C$. pacifica KMM $3879^{\top}$. a) Bone-marrow-derived macrophages (BMDMs) from wild-type C57BL/6 mice were stimulated with the LPS of $C$. pacifica KMM $3879^{\top}$ or E. coli (0111:B4) at concentration of 1,10 , and $100 \mathrm{ng} / \mathrm{mL}$. b) Human peripheral blood mononuclear cells (PBMCs) were stimulated with $10 \mathrm{ng} / \mathrm{mL}, 1 \mathrm{ug} / \mathrm{mL}$ and $10 \mathrm{ug} / \mathrm{mL}$ of $C$. pacifica KMM 3879 $\mathrm{T}$ LPS, or E. coli O111:B4 at concentrations of 1,10 and $100 \mathrm{ng} / \mathrm{mL}$. Significant difference between the LPSs is indicated by ${ }^{*} p<0.05$, ${ }^{* *} p<$ $0.01,{ }^{* * *} p<0.001$ by the Student's $t$-test.

Figure 8. Stimulation of HEK 293-hTLR4/MD-2/CD14. Fold of activation of NF-KB (a) and CXCL-8 (b) upon stimulation with 1,10 , and $100 \mathrm{ng} / \mathrm{mL}$ with LPS of $C$. pacifica KMM $3879^{\mathrm{T}}$; E. coli (0111:B4) was used as a control. Significant difference between $C$. pacifica KMM $3879^{\top}$ LPS generated values and the corresponding $E$. coli LPS values are indicated (C. pacifica KMM $3879^{\top}$ LPS vs. E. coli LPS) $\left({ }^{*} p<0.05,{ }^{* *} p<0.01,{ }^{* * *} p<0.001\right)$.

Figure 9. Competition assay. (a) Fold of NF-KB activation and (b) CXCL-8 release in HEK 293-hTLR4/MD-2/CD14 stimulated with different concentrations $(1,10$, and $100 \mathrm{ng} / \mathrm{mL})$ of $C$. pacifica KMM $3879^{\top}$ LPS and then restimulated with $10 \mathrm{ng} / \mathrm{mL}$ of $E$. coli LPS. Significant difference between the LPSs is indicated by ${ }^{*} p<0.05$, ${ }^{* *} p<$ $0.01,{ }^{* * *} p<0.001$ by the Student's $t$-test.

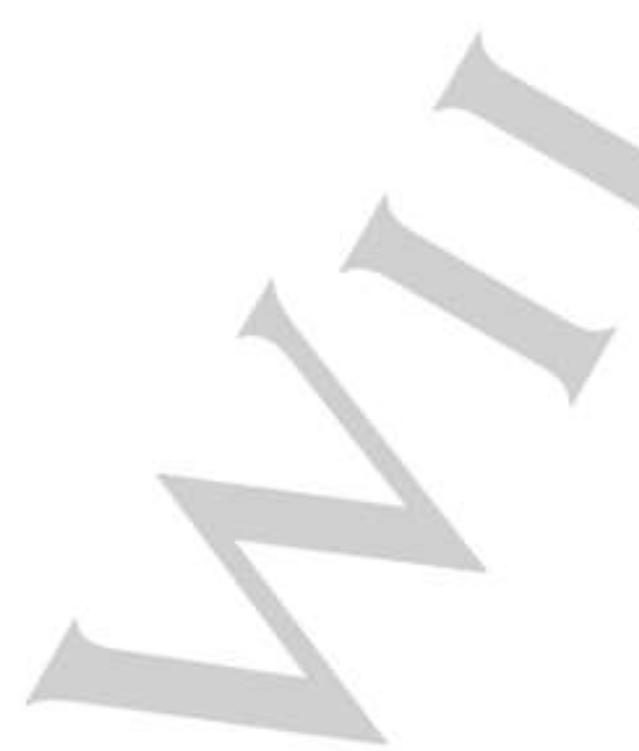




\section{WILEY-VCH}

\section{FULL PAPER}

\section{Figure 1}

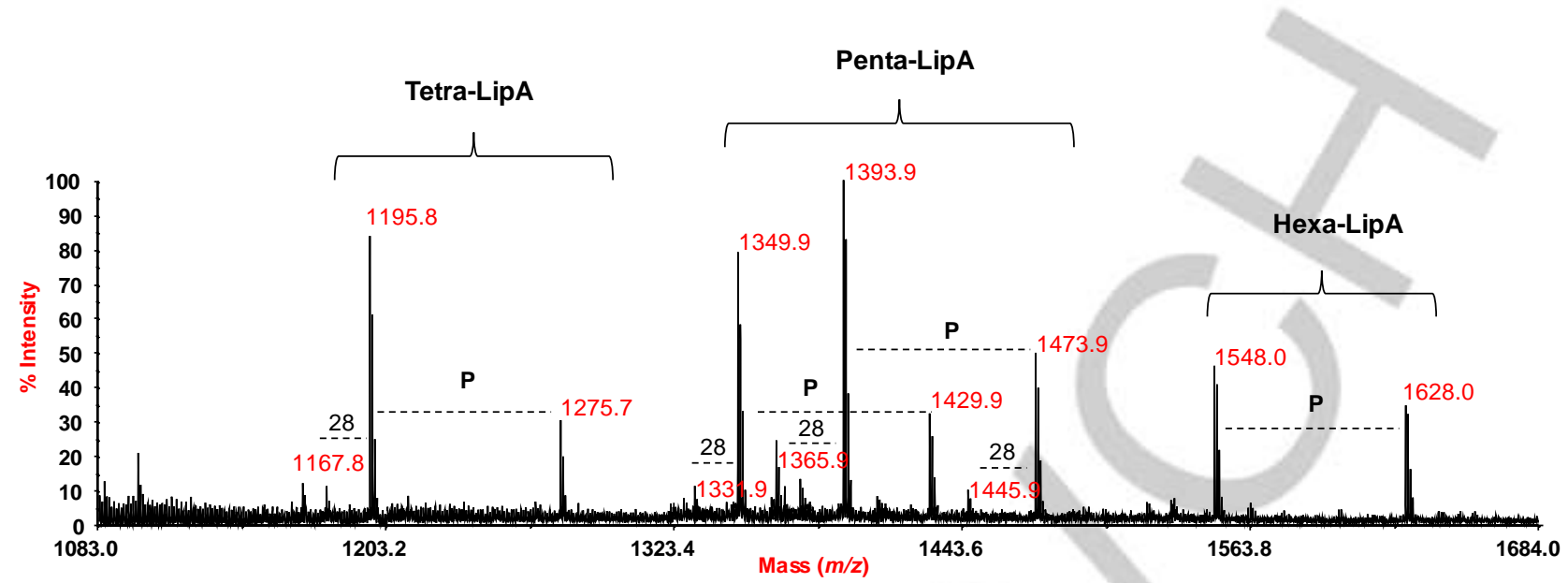




\section{FULL PAPER}

\section{Figure 2}

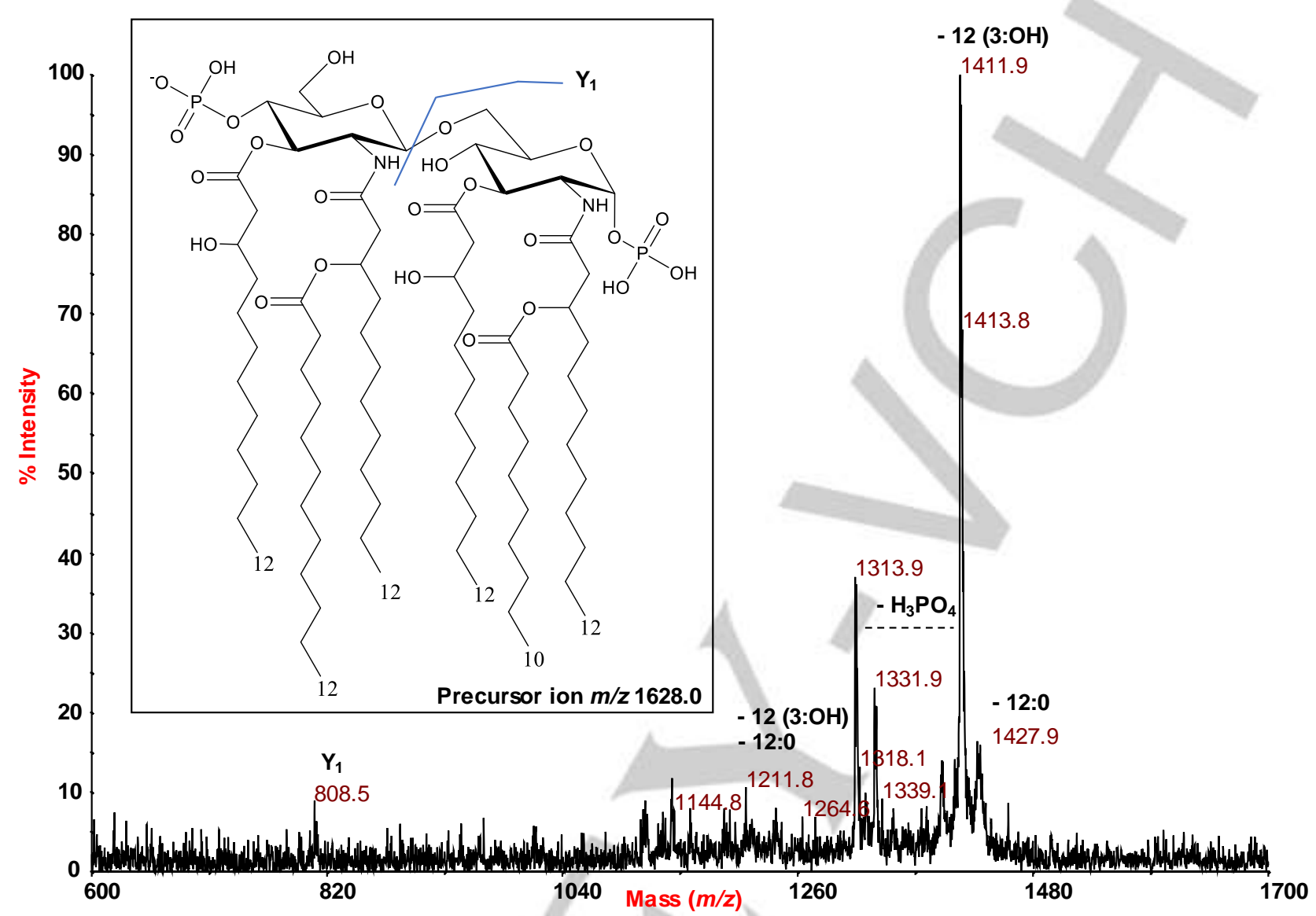




\section{FULL PAPER}

\section{Figure 3}

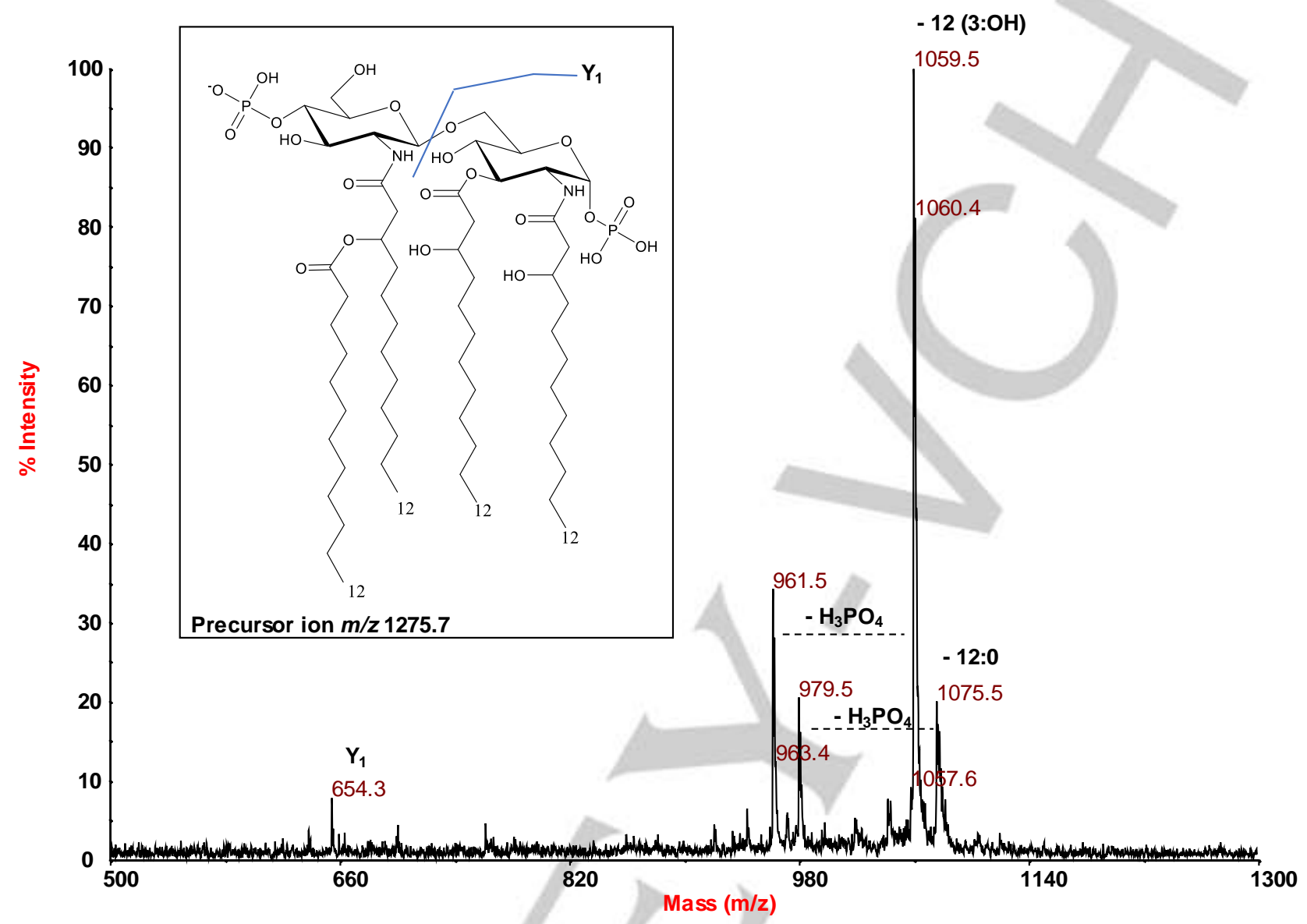




\section{FULL PAPER}

\section{Figure 4}

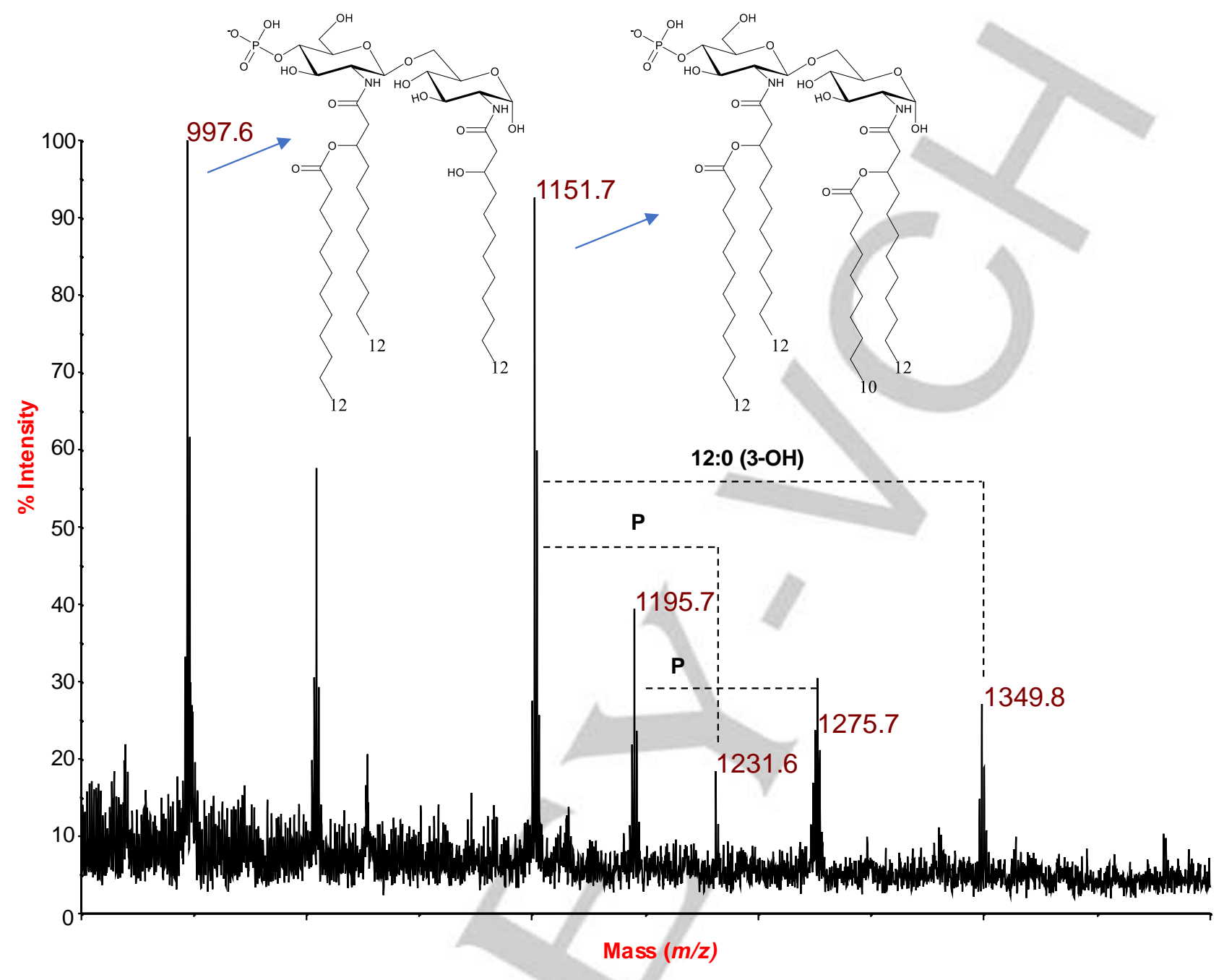




\section{WILEY-VCH}

\section{FULL PAPER}

\section{Figure 5}

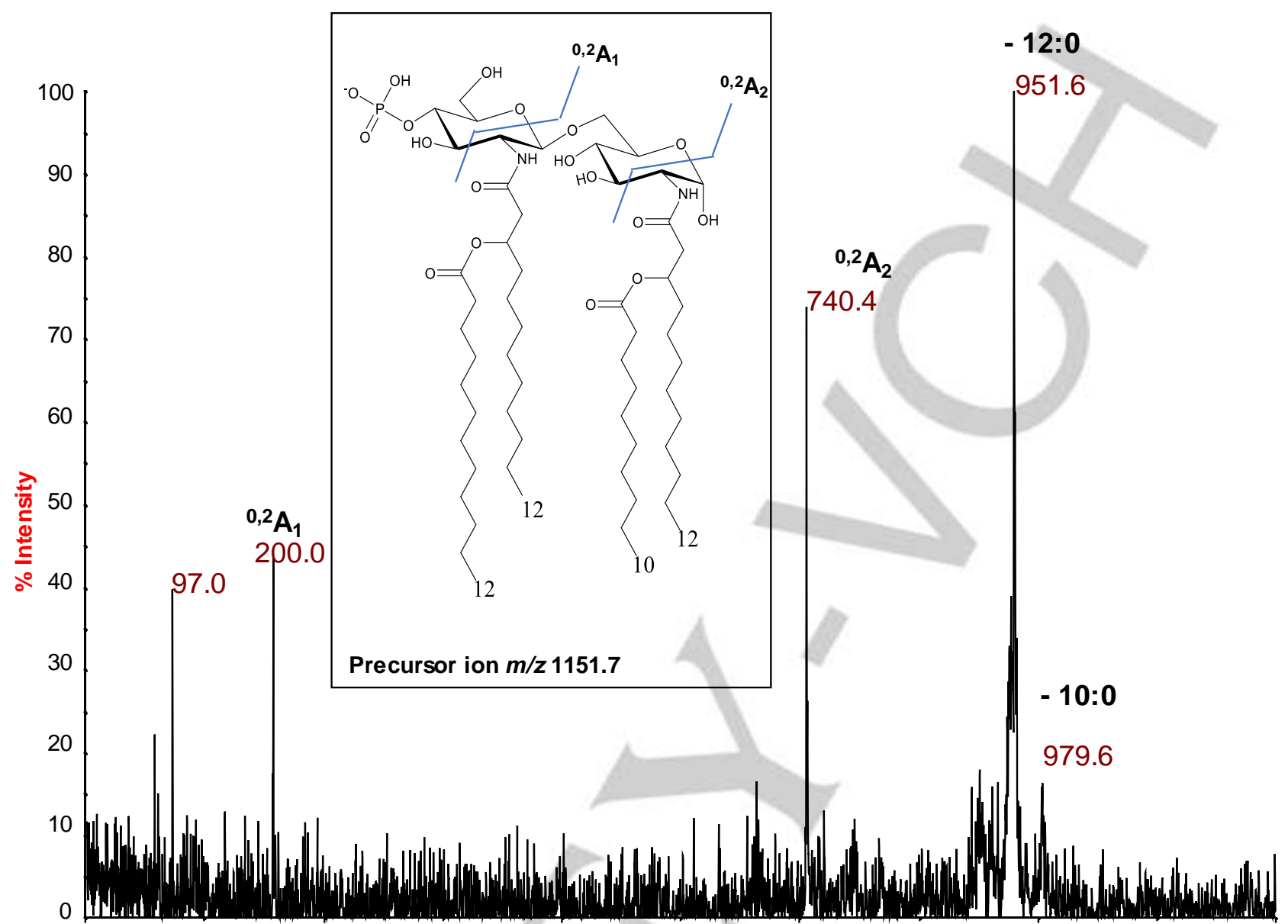

Mass $(m / z)$ 


\section{WILEY-VCH}

\section{FULL PAPER}

\section{Figure 6}
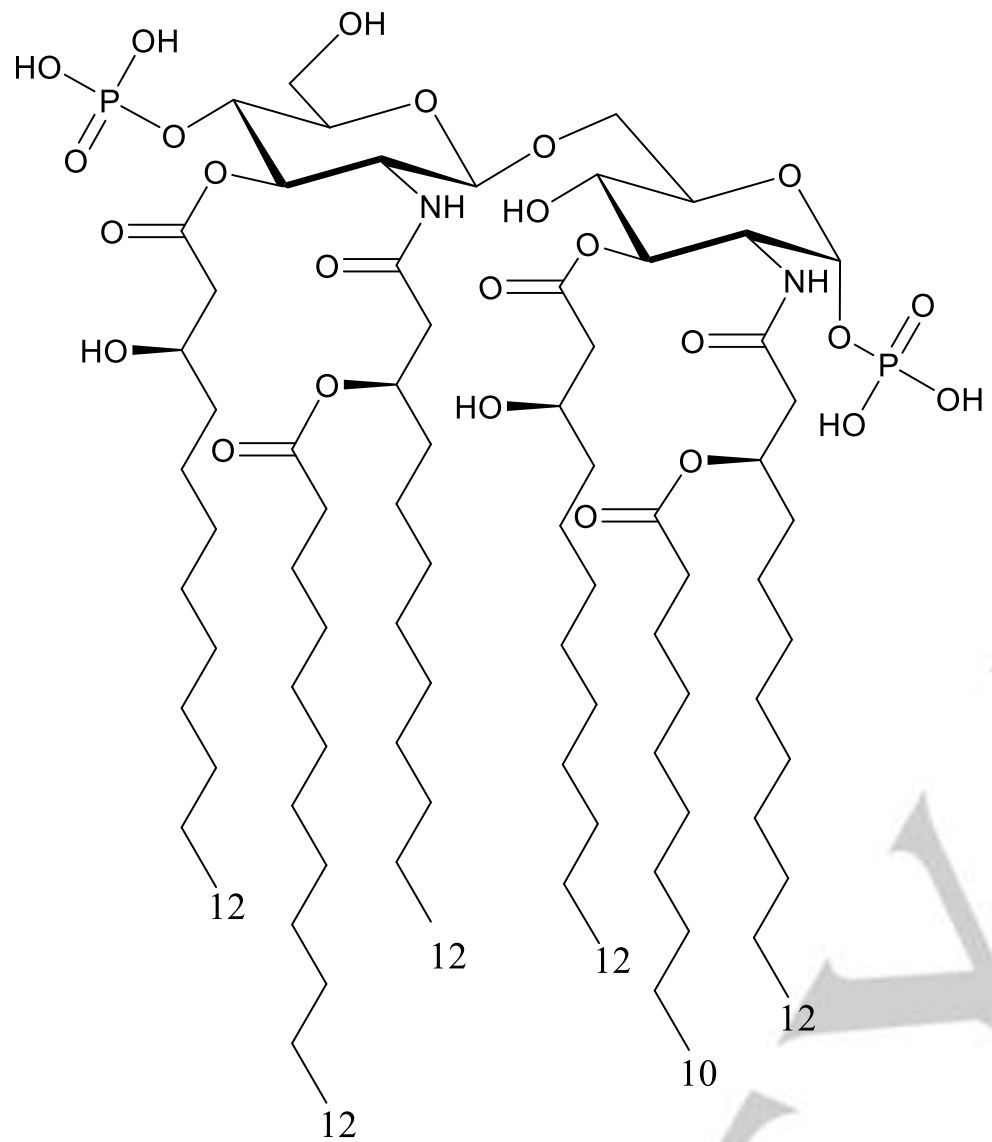

12

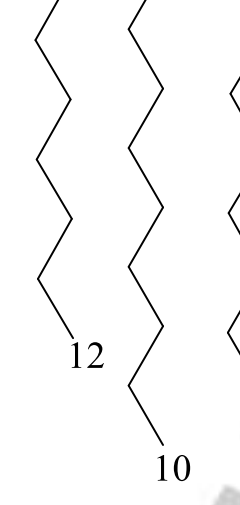

12 


\section{WILEY-VCH}

\section{FULL PAPER}

\section{Figure 7}

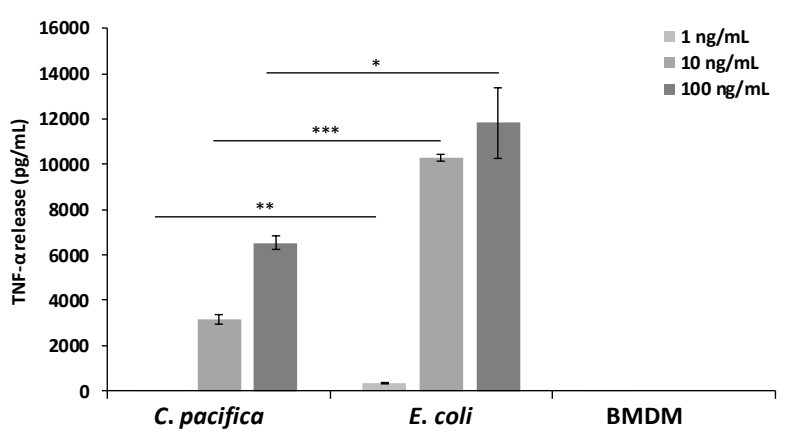

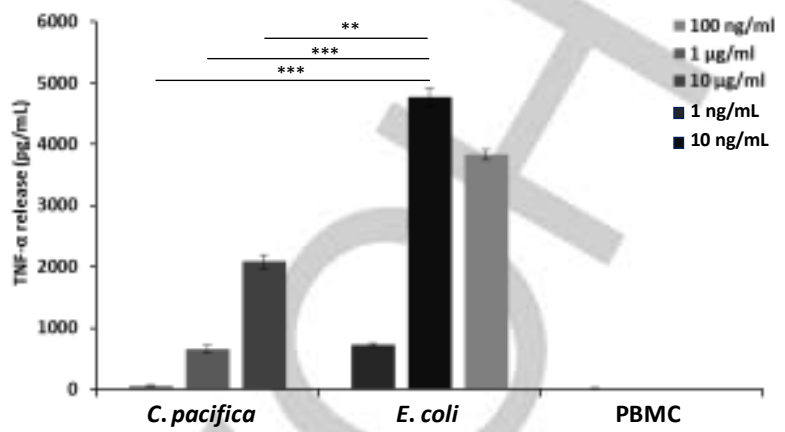




\section{WILEY-VCH}

\section{FULL PAPER}

\section{Figure 8}
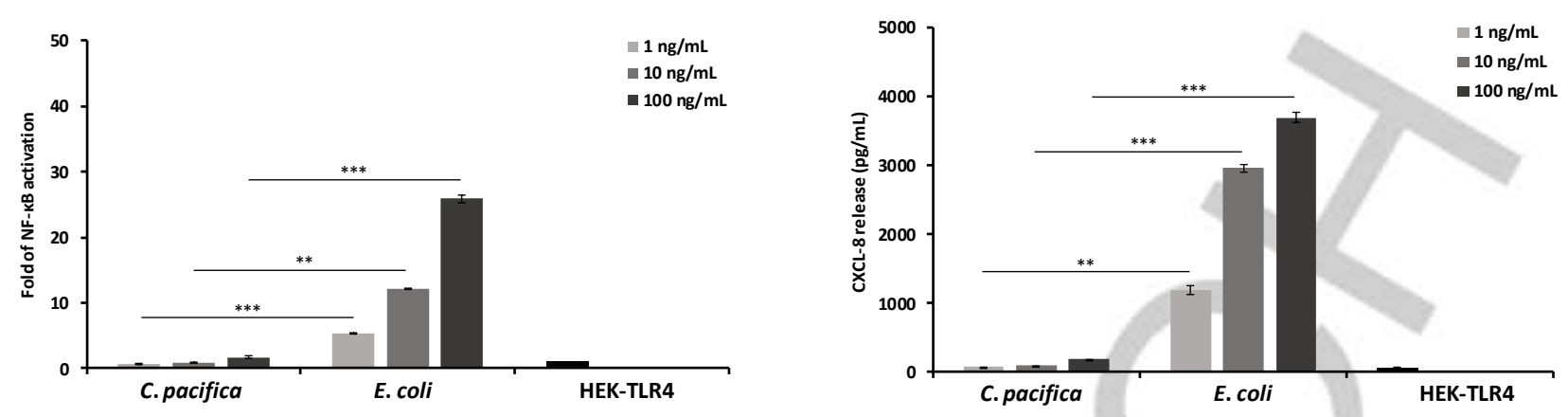


\section{WILEY-VCH}

\section{FULL PAPER}

\section{Figure 9}
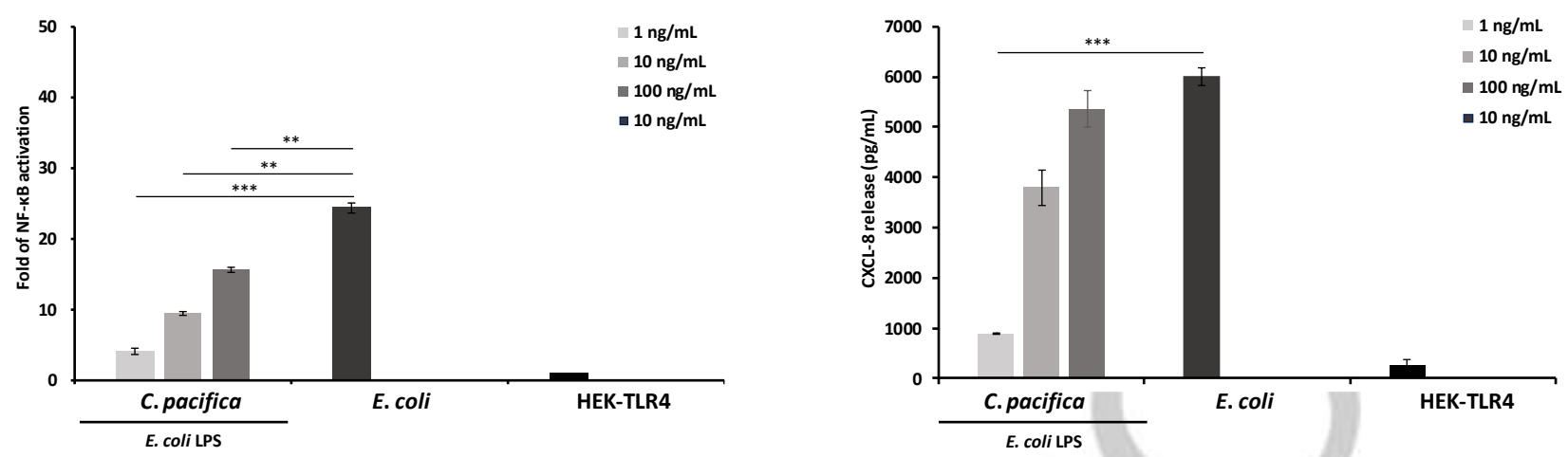
WILEY-VCH

\section{FULL PAPER}

The structural and bioactivity elucidation of LPS from marine bacteria is an appealing research field from the perspective of conception of new generation drugs. Here we show that Cobetia pacifica KMM $3879^{\top}$ LPS expresses a complex family of lipid A species. Immunology studies on the LPS highlighted a low immunoactivity and a good inhibitory action towards toxic LPS.

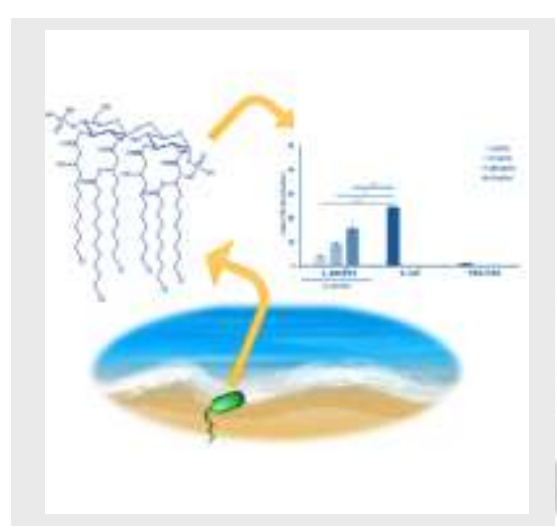

Marine Bacteria Lipopolysaccharides*

Flaviana Di Lorenzo, * Angelo

Palmigiano, Sami Albitar-Nehme,

Mateusz Pallach, Maxim Kokoulin,

Lyudmila Romanenko, Nadezhda

Komandrova, Domenico Garozzo,

Maria-Lina Bernardini, Antonio Molinaro,

Alba Silipo*

Page No. - Page No.

Lipid A structure and

immunoinhibitory effect of the marine

bacterium Cobetia pacifica KMM

$3879^{\top}$ 